\title{
Strategy for Co-Creation of Value with Consumers
}

\author{
Sara J. Garski \\ Capella University, Minneapolis, USA \\ Email: sjgarski@yahoo.com
}

Received 18 January 2014; revised 20 February 2014; accepted 25 March 2014

Copyright (C) 2014 by author and Scientific Research Publishing Inc.

This work is licensed under the Creative Commons Attribution International License (CC BY). http://creativecommons.org/licenses/by/4.0/

c) (i) Open Access

\begin{abstract}
Organizations are seeing the value in comprehensive strategic planning as a result of economic difficulties and the need to become more innovative and viable. The relationship that an organization creates with its customers is the key to its ultimate survival and success. The strategies and tools discussed in this paper provide an overview of what the literature has proven to be some of the most effective ones in today's competitive environment.
\end{abstract}

\section{Keywords}

Component; Formatting; Style; Styling; Insert

\section{Strategy for Co-Creation of Values with Consumers}

Strategy is a plan of action that takes into account current resources and future goals [1]. Strategies are used to develop and plan how to achieve long term goals, increase competitive advantages over other companies, and which resources and milestones are needed to make the strategy effective. Strategies also take into account any possible negative effects that arise from planning to achieve a goal. If a long term goal is to increase competitive advantage over other companies, a negative consequence could be an increase in spending. The company needs to determine if the increase in spending to achieve the goal is worth using that type of strategy.

Strategies try to identify the best plan to reach a goal. In some situations, a final goal can be achieved in a variety of ways, but it is likely that there is one option that is better than the rest [2]. All options should be considered when developing a strategy to determine which option meets all or most of the goals in the best manner.

One common goal of most companies is to gain a strong customer base.

Currently, most companies have a variety of competitors, so it is vital to create a customer base that is loyal. An option for creating this type of customer base is to work with the customers so that they feel valued by the company [3]. Co-creation of value can be achieved by using a variety of strategies and tools. 


\section{Stakeholder Theory}

The stakeholder theory takes into consideration the needs and desires of everyone who is invested in the success of a company. This can include the stockholders, managers, employees, and consumers of the company. The use of this theory can assist companies in determining how to be profitable and still consider the input from a variety of different perspectives. Although, considering this theory does not necessarily give consumers direct input into the future of the company, it still provides the company with an opportunity to make decisions about how their decisions will affect consumers and ideally gain loyalty and attract new consumers. This in turn would increase the profits of the company which would benefit employees by providing stable employment, managers would have a larger budget to work with, and the stockholders would receive financial rewards.

\section{Target Market}

When market managers decide upon the target customer, they should be making the decision two folds; will this product sell to make the company money and will the consumer benefit from it [4]. Many times the first answer is the prominent answer, thus, the consumer is left defending themselves. An example of a poor target audience is credit cards offered to adults soon after high school. Many companies provide the card at an introductory rate, until the credit limit is reached or a payment is late. Then the rate of the card escalates because of the reasons in the fine print.

Target market can be broken down into several categories such as demographics, geographic and lifestyle factors along with customer needs [4]. Each plays an important role in creating a campaign to build customer loyalty. To understand the demographics, an organization needs to know what types of people are in the market and develop a plan to reach the group. The size of the organization will factor into how large of a demographic scope organization needs to entail. The geographic and lifestyle factor also plays a role for the desired target market. It also identifies how to best approach that group. Customer's needs identify why a consumer might purchase the organization's product or service.

Target marketing can make promotion, pricing, and distribution of products and services easier and more cost effective for the organization [4]. It identifies a core group of potential consumers for the organization. When the target market is identified, the organization needs to actively pursue the group. It then needs to build customer loyalty which the organization should try to keep and build upon for future transactions as well.

\section{Diversification}

Diversification is used to strengthen a company by offering other options to consumers [5]. This in turn will increase the shareholder values. Diversification can occur through acquisition, internal start up, and joint venture or internal partnerships. Diversification can lead to a related or unrelated product.

When a company acquires another business, the product of the new business can be either related or unrelated [6]. If the product is related, it will be easier to integrate the new company into the existing company.

Internal start up is the initiation of a new business from scratch [6]. This means that a company that focuses on making soap could diversify by starting a new branch of the company that makes some type of food. These two products are unrelated, so the company has to start the new product from scratch.

Joint ventures are when two or more companies work together to create a new product. This can be helpful when two companies have limited resources but agree on the need for a new product [6].

\section{Differentiated Services}

Many companies are trying to differentiate themselves from the competition by showing people the benefits of their product [7]. This is good for the select people that actually need the product but the group that purchases the product because that the person sell it or because that they believe this product will improve their lives, and need to take some time and review their needs and wants [2]. A market manager may not have intended for this group of people to purchase the product, but will not turn down the market share.

Differentiation strategy works best when the needs and uses of a product are diverse, when there are many different ways to differentiate the product or services, so the buyer perceives the differences as having value, when there are few rivals or competitors using a similar differentiation approach, and when technological change is fast-paced. It is important for the customer to find value in the product [7]. This helps to build loyalty 
to the product and to the company. There are several brand names that easily attract customers to their new products because customers show loyalty to the other products that the name sells. However, the company needs to continue to only sell products that are the same level of quality as the original to maintain the customer base and reputation of the brand name.

However, using a differentiation strategy can sometimes harm the company. This can happen if competitors can easily follow or copy the plan and product. When this happens, the competitors can usually offer the product for a cheaper rate because they do not need to spend the time or money to develop the product or plan [7]. If a company spends too much on research to differentiate their products, it will erode much of the profit gained from the differentiation. There is also risk associated when consumers do not find the differentiation to be of any use [2]. As soon as a customer no longer finds value in a product, the company is in trouble because the consumer will find another product on which to spend his or her money.

\section{Competitive Advantage}

Creating a competitive advantage is a way for companies to create a larger customer base and at the same time create loyalty among the consumers. If consumers feel that a company values them, they may be more likely to see the value in the company and its products.

Drawing a rival out of the profit zone is one way to create a competitive advantage [8]. This can be done by purposefully losing a customer base that is less profitable. This allows the firm to then target the higher profitable customers. A firm will create a product that is useful to several people, but very unprofitable and then makes the product known to other companies. The other companies then create the same product and sell it to the lower income consumers. At the same time, the original company is targeting the higher income consumers with a different type of product. Most companies watch their competitors to determine what new products or methods they are using, and then they try to copy these ideas so that they can also make a profit and not fall behind. This can create a stronger customer base because there will be fewer competitors since potential competitors will be focusing on other less profitable products.

Employing unfamiliar techniques is another way to be creative and create higher profits [8]. When a proven technique works for one industry, a firm may try it in another. The competitors in the market will be wary of trying the new technique for fear of losing rather than gaining profits. If the technique works it will give the firm a competitive advantage. An example of this technique would be to offer incentives.

Disguising success is a very useful way of creating a competitive advantage [8]. If competitors think they do not need to worry about the success of another company, they will try less to keep and gain customers. If a company quietly grows, it does not have to worry about competitors trying to copy its techniques. Eventually, the company will be recognized as a larger force, but by that time, the company will already have established a large, loyal customer base.

Globally, employees are able to gain competitive edges through technology and increased competitiveness. This also means that it is more difficult for a company to retain its competitive edge because companies are always trying to get the upper hand on the competitors [8]. In order to maintain the competitive advantage, the company must always be aware of what their competition is implementing and have a task force of creative employees to ensure that the company is either keeping up with or ahead of current trends.

Vertical integration is when a company expands its value change by adding suppliers or consumers. The more suppliers and consumers that a company has, the greater competitive advantage of the company [9]. They are reducing the number of competitors, and as they become larger, they have more profits which can give them more opportunities and abilities to make decisions that will give them more advantages.

The advantage of vertical integration is that obtaining a new supplier can lower the cost of purchasing materials from other suppliers [9]. The supplier no longer needs to make a profit, so the added expense of the supplier profit is eliminated and becomes part of the profit of the entire company. It also shows other independent suppliers that the company does not need to purchase from them, and thus they may lower their price for the company. Acquiring another company can also increase the number of consumers. The consumers that are loyal to the acquired company will hopefully remain loyal to the larger company once the acquisition is complete.

A disadvantage of vertical integration is that acquisitions do not always perform well. If a supplier cannot keep up with the need of the company, it may be more difficult for the company to find other resources to produce the product efficiently [5]. If a company acquires another company that is not doing well, their reputation 
may be at stake because consumers familiar with the acquired company may view the larger company as having the same issues as the acquired company.

\section{Product Life Cycle}

The stages of a product life cycle are market development, market growth, market maturity, and market decline [10]. All products go through this cycle, but this occurs at different rates. Some products are based off trends and go through their life cycle in a few months while other products stay on the market without changing for several decades.

During the market development stage, the company decides if it wants to be a first mover and create a new product, or to be a slow mover and allow other companies to come up with the idea and then develop said ideas [10]. As a first mover, the cycle may be impacted by a change in technology. The technology can either assist in making the new product, or if the product is already made, it can stop the production of the product if technology has replaced the need for the product. If there is an increase in resource availability, this may aid in the creation of a new product. As more competitors enter the market, the cost of resources may increase with the increased need from other companies.

During the market growth phase, the first movers are starting to realize profits as more consumers are purchasing the new product [10]. An increase in technology could increase the rate at which the product is produced, and in turn expand the areas where the product is sold and reach more consumers. When the market is growing, having enough resources is important to continue increasing the amount of product produced. If there were not enough resources, it would be difficult for the product to have market growth because there would not be enough products to introduce into new market areas. As the market grows, more competitors will enter the market to find a piece of the successful products' profit.

The market maturity phase involves a saturation of the market [10]. At this point, a company is trying to maintain its market share, so the introduction of more competitors can hurt the company.

The fourth stage is market decline. During this stage the popularity of the product decreases [10]. This can be a result of technology that provides a substitute or alternative to the original product. Every product has a life cycle, so a company knows that eventually the products life will end. The company needs to be working towards finding new products to enter into the market so that there is always growth within the company.

Consumers have some power in how quickly a product moves through the life cycle. As long as the consumer remains interested in the product and finds the product to be valuable, the product will remain in the market growth and market maturity phases. However, this will only happen to products that are truly unique and useful. The product will need to have few. If any, competitors so that the company can continue to focus on making the product at a lower cost and continue to make a profit.

\section{Intellectual Capital}

Intellectual capital will always be the most important investment. Without the minds and knowledge of intelligent people, production plants, equipment, and other assets would be worthless [11]. Companies need competent employees who know how to run plants or work equipment. It is possible that as technology continues to develop, fewer employees will be needed in some businesses. However, at this point, it will not be possible for a company to run completely on its own. It will require some people with knowledge of how to fix equipment or who have plans on how to use equipment.

If a company does buy a new plant and new equipment, it is very important to have managers who know how to use the equipment and manage the plant so that money is not wasted and the equipment is used properly. Intelligent managers can help increase efficiency through positive employee relationships. They can increase morale and create a positive organizational culture which in turn can motivate employees to do their job well. Another benefit of intellectual capital is the ability to critically think and come of up with new ideas. Computers and equipment cannot think of new ideas on their own. Computers can only give out information that someone has put into them.

\section{Best Practices}

Best practice is the idea, technique, method, process, activity, incentive or reward to deliver a particular outcome 
over other ideas, techniques, and methods [12]. With the proper processes, the desired outcome can be achieved with fewer problems for the organization. It may also lead to enhanced outcomes for the organizations.

The best practices can eventually become rules that an organization follows to build customer loyalty and increase the preceded value [12]. It would take time, but the practices can be deemed effective and further incorporated for the betterment of the organization. The rules can also be standards practiced across the board in similar organizations.

Any organization can use best practices to enhance customer service. The changes need to be charted and documented to properly evaluate the practices' effects. Some of the best practices can be put into place in a short term or long term time frame, but the practices need to be properly installed for the best results.

The practices can come from anyone inside the organization or even be a recommendation from a consumer [12]. A potential best practice can be something learned from a SWOT analysis. It could be a strength that can be further enhanced with a new practice or an internal change to improve a weakness. The practice could also be viewed as an opportunity to build value and loyalty. A threat could be adverted with a best practice as well.

Organizations need to establish the practices to keep improving on their services. Anytime an organization does not look to enhance services, customers may look elsewhere for those services, which in turn hurt the organization.

The key idea of best practices is to enhance the organization's performance which can lead to additional customer loyalty and perceived value. It can also lead to additional opportunities to reach new consumers which will add revenue.

\section{Information Systems}

An information system is a broad reaching system of data that deals with important shareholders of the organization [4]. It covers five broad areas of data that deals with, customers, operations, employees, financial performances and supplier/partner/collaborative ally. All key strategic performance indicators have to be tracked by the organization to better understand the market and make strategic decisions about the future of the company.

Customer data is important for the organization because it shows who buys the products provided. The customer data also shows who is not purchasing the product and that segment of consumers can be targeted by the organization if desired [4]. The data should show a representation of customers of the organization. If other segments are targeted, a campaign should be established to find out how the consumers could be enticed to purchase goods.

It is also important that an organization keeps customer data private and not release it to other organizations. Customers generally do not want their information released to others when they consider it confidential [5]. With recent increases in identity theft, consumers depend upon the confidentiality of the company from which they purchase products or services. Often, organizations sell information about consumers to other companies for various reasons, but it is not advised. If a consumer knows an organization sold or distributed information, the lack of trust would affect the company negatively especially if it spreads to other consumers.

Companies can share best practices information to improve the market, but customer information should not be provided under any circumstance. The best practice information can help upstart or struggling organizations. Also, the best practices information could be a benefit to other organizations outside the market to reach new heights by using methods employed in other industries.

\section{SWOT}

An organization should use an SWOT analysis before implementing any sort of strategy. The SWOT analysis provides a blueprint of where an organization stands in terms of its strengths, weaknesses, opportunities, and threats internally and externally. The analysis is something the organization should keep up to date with the latest changes that may affect shareholders. Also, for a fair SWOT analysis, the organization should not aim for a predetermined result, rather, collect the data and form objectives from the analysis. The entire analysis should be done internally to better understand the business environment. Strengths and weaknesses hold internal origins while opportunities and threats are external factors. The four can also be broken down into two additional categories: helpful and harmful. The two helpful sections are the organization's strengths and opportunities. On the other hand, weaknesses and threats are harmful to the organization. 


\subsection{Strengths}

In the analysis, the strengths are all positive aspects of the organization, such as location, product, and marketing and other attributes or characteristics that are considered to be important for the success of the organization are strengths. This is the areas that the organization is already taking advantage of. The resources and capabilities that can be used for an advantage are also considered strengths. Other aspects that add value to a product and service are considered strengths. After the strengths are identified, the organization needs to establish how to better utilize each. Also, some of the strengths could be already established while others might need to be further developed. The strengths should be broken down by area in the organization to better identify each. There is no limit to where the strengths can come from, such as people, location, products, and reputation. A company should try to use its strengths to build customer loyalty by promoting its strengths through marketing.

\subsection{Weaknesses}

The weaknesses appear in the shortfalls the organization faces. All weaknesses are factors that the organization controls and detracts from the ability to maintain a competitive edge. Also, absences of certain strengths can be considered weaknesses by the organization. The weaknesses need a quick remedy from the company. Each weakness captures the negative aspects internally in the organization. All weaknesses are factors under the organization's control but need to be improved to accomplish the goals of the company. The weaknesses need to be enhanced in order to transform into strengths and compete within the market. The more accurate the analysis, the more valuable the identification of weaknesses can be. Consumers are usually aware of the weaknesses of a company, but the company should try to work on the weaknesses and present them minor issues.

\subsection{Opportunities}

Opportunities are the places where the organization can place their product or expand the company to better serve a purpose which can generate additional revenue. Also, aspects that are external elements that could prove helpful in achieving the goals of the organization are opportunities. As part of the external environmental analysis, additional opportunities may be apparent for additional profit and growth. Opportunities may arise from market growth, lifestyle changes, or positive market perceptions. Other factors can expand opportunities for an organization. Each of the opportunities needs to be organized by priority. The first priority should be given to the opportunities where the effectiveness is possible. Opportunities can also be considered potential that the organization can realize just by implementing a plan that slightly alters the internal functions of the company. In all, opportunities are abundant and the organization must develop a plan to capitalize on each. Opportunities also bring a level of risks for the organization. The risks should be looked at during the prioritizing of opportunities. Companies can look to the consumers for opportunities. This can be done by studying consumer trends or doing studies with a test group. If consumers have input into the products a company produces, it is more likely that they will remain consumers of that product and company because they will feel a sense of ownership.

\subsection{Threats}

The threats to an organization are the competition, market, economy or any other factors that can significantly hurt the organization in the short or long term. All threats are external environmental changes and could do damage to the organization's performance. The threat could be created by an unfavorable trend that leads to revenues or the fall of profits. Each needs to be analyzed to determine if it is possible to defend against the threats. It offers threats that the organization needs to develop a counterattack against. Threats can also be categorized into serious and probability of occurrence. This will help determine which threats should be looked at closely and which can be put on hold for the time being. The better an organization can identify potential threats, the more likely the organization can position a proactive plan to respond.

All four factors should be looked at to better place products, locations, and employees among other factors for the betterment of the organization. The analysis should include all departments of the organization for a total understanding.

\section{Short Term Rewards}

Short Term Rewards are ways for organizations to draw in consumers [13]. A store may offer extreme discounts 
in order to draw in more consumers. Other rewards could be offered, such as perks. The rewards cost the company in the short term, but they also draw additional consumers which can raise profits. It can be seen as a way to move products that need to be moved such as year-end models. On the flip side, the rewards can be part of a promotion to introduce a new product.

The rewards can be seen as a way to build loyalty towards a brand and organization [13]. The organization has to make sure the reward as well as their product meets the consumers' needs. If the reward is not up to standard, the consumer will remember the organization negatively. It will not be as harsh if the original product meets or surpasses expectations.

The costs of rewards are normally overlooked by the organization in order to try to sell additional units. The organization is willing to spend money in order to make more with additional sales. The rewards should draw consumers that are not as familiar with the products the organization have.

The employees of the organizations may also be rewarded with short term rewards. The employees may receive rewards for job performance. The rewards could boost morale in the organization and happy employees can lead to happy customers. Rewards for employees and customers should not be offered at the same time due to the additional cost for the organization unless the costs could be covered.

Short term rewards have many aspects that an organization needs to study before offering them internally or externally. The proper placement and distribution of rewards can greatly enhance the organization.

\section{Emergent Approach}

The rational planning model is about determining which steps need to take place in order to reach a final goal [14]. The purpose of having a plan is having a guaranteed way of reaching a goal. If each step of the plan is followed, the goal should be accomplished. Problems arise when the steps do not lead to reaching the final goal. When this happens, the company needs to be adaptive and change the plan or find a new plan that will lead to reaching the goal.

In the emergent school, goals are less straight forward and decisions are made based upon the changing environment of the situation [14]. It is much more adaptive because it does not involve steps that need to be followed. This type of approach would be beneficial to companies that offer diverse products or services and does not sell one strict product or service.

\section{Conclusions}

The strategy that will assist in the co-creation of value is the emergent approach. The emergent approach is adaptive and thus allows more input flexibility from consumers. However, other strategies should be used in conjunction with the emergent approach. The stakeholder theory discusses the input from all stakeholders in a company including the consumers. This theory should be strongly considered when creating a strategy of co-creation of value because it directly takes into consideration the needs of the consumers. If a company decides to conduct a SWOT analysis, it can provide opportunities for consumers to give their input about what changes the company could make. It could also show which opportunities are available for exploration that may be more attractive to current or potential consumers. If a company carefully diversifies or differentiates its services, customers can find new values in the company because they are offering more useful opportunities. Not all products or services may be useful to the consumer, but when diversification occurs, it provides more opportunities to attract new consumers with new products.

When creating a strategy, companies should consider the best practices that other competitors in their field are using. Companies can use the ideas found in the best practices to expand and create new ideas that will be attractive and valuable to the consumers. However, they should be aware that when they build on or create new best practices, it is likely that other competitors will also use those new ideas.

Protecting the information systems that contain customer data is necessary for the consumers' safety. When a company shares consumer information with other companies, it costs the consumer time in answering phone calls or sometimes in battling the effects of identity theft. Thus, having a policy that restricts the sharing of consumer information with other companies and protecting it from potential hackers is the value to consumers and should be part of the value building strategy.

Consumers now have several options when it comes to choosing companies and businesses from which to purchase products and services. Thus, successful companies will work with consumers by listening to their 
wants in addition to their needs to provide a product and company that consumers find valuable. If consumers do not find the company and product to be valuable, they will most likely choose to delegate their finances to other industries that are more valuable to them. Thus, the importance of co-creation of value should not be overlooked when creating a strategic plan.

\section{References}

[1] Porter, M. (1980) Competitive Strategy: Techniques for Analyzing Industries and Competitors. Free Press, New York.

[2] Mintzberg, H. (1994) The Rise and Fall of Strategic Planning. Free Press, New York.

[3] Prahalad, C.K. and Ramaswamy, V. (2004) The Future of Competition: Co-Creating Unique Value with Customers. Harvard Business School Press, Boston.

[4] Caragher, J.M. (2008) Expand Your Horizons: Niche Marketing Success Stories. Journal of Accountancy, 205, 56-61.

[5] Thompson, A., Strickland, A. and Gamble, J. (2005) Crafting and Executing Strategy: Text and Readings. McGrawHill, New York.

[6] Hoopers, D.G. (1999) Measuring Geographic Diversification and Product Diversification. Management International Review, 39, 277-292.

[7] Larsen, P., Tonge, R. and Lewis, A. (2007) Strategic Planning and Design in the Service Sector. Management Decision, 45, 180-193. http://dx.doi.org/10.1108/00251740710727232

[8] Stalk, G. (2006) Curveball Strategies to Fool the Competition. Harvard Business Review, 84, 114-122.

[9] Ho, C.H. (2007) Identifying Stakeholders' Positions through Value Creation System. The Business Review, Cambridge, 7, 254-262.

[10] Levitt, T. (1965) Exploit the Product Life Cycle. Harvard Business Review, 43, 81-94.

[11] Nazari, J.A. and Herremans, I.M. (2007) Extended VAIC Model: Measuring Intellectual Capital Components. Journal of Intellectual Capital, 8, 595-612. http://dx.doi.org/10.1108/14691930710830774

[12] Clark, G.L. and Urwin, R. (2008) Best-Practice Pension Fund Governance. Journal of Asset Management, 9, 2-21. http://dx.doi.org/10.1057/jam.2008.1

[13] Wang, W.H. (2008) The Interrelationship of Retailer's Relationship Efforts and Consumers' Attitude and Behavior. Measuring Business Excellence, 12, 13-28. http://dx.doi.org/10.1108/13683040810864350

[14] Downs, A., Durant, R. and Carr, A. (2003) Emergent Strategy Development for Organizations. Emergence, 5, 5-28. http://dx.doi.org/10.1207/S15327000EM050204 